\title{
Comparison of SSSC and d-q Control Scheme based UPFC for Power Flow Control
}

\author{
D. Murali \\ Research Scholar in EEE Dept., \\ Government College of Engineering, \\ Salem-636 011, Tamilnadu, India.
}

\author{
Dr. M. Rajaram \\ Vice Chancellor, \\ Anna University of Technology, \\ Tirunelveli-627 007, Tamilnadu, India.
}

\begin{abstract}
The control of power and the usable capacity enhancement of present as well as new and upgraded lines can be effectively done by Flexible alternating current transmission systems (FACTS) technology. The Unified Power Flow Controller (UPFC) is a second generation FACTS device which enables independent control of active and reactive power besides improving reliability and quality of the supply. This paper describes the independent control of real and reactive power flow through a transmission line by using the $\mathrm{d}-\mathrm{q}$ (direct axis-quadrature axis) control strategy for UPFC placed at the sending end of an electrical power transmission system. The $\mathrm{d}-\mathrm{q}$ control scheme is based on the transformation of a three-phase system to d-q two axis system. The power flow control performance of the d-q control scheme based UPFC is compared with that of the other FACTS device called Static Synchronous Series Compensator (SSSC) by applying a single line-to-ground fault across a transmission line to which they are connected. Simulations are carried out in Matlab/Simulink environment to validate the performance of the $\mathrm{d}-\mathrm{q}$ control scheme for UPFC. The simulation results show that the $\mathrm{d}-\mathrm{q}$ control scheme based UPFC is more effective than SSSC in controlling the real and reactive power flow.
\end{abstract}

\section{Keywords}

FACTS, Matlab/Simulink, Real and reactive power flow, SSSC, UPFC.

\section{INTRODUCTION}

It is essential to improve electric power utilization in today's highly complex and interconnected power systems, while still maintaining reliability and security. Since in power systems some of the transmission lines have power flows well below their normal limits and other lines are overloaded, voltage profiles are deteriorated and system stability and security are decreased. To meet the needs of power transfer, it therefore becomes more important to control the power flow along the transmission lines. Nowadays, the technological stage of high power solid-state power electronic devices has made FACTS (Flexible alternating current transmission systems) a promising pattern of future power systems to enhance system stability and to achieve better utilization of existing power systems.

Power flow between two buses of a lossless transmission line is given by:

$$
P_{i j}=\frac{V_{i} V_{j}}{X_{i j}} \sin \delta_{i j}
$$

where, $V_{i}$ and $\delta_{i}$ are the $i^{t h}$ bus voltage magnitude and angle, $V_{j}$ and $\delta_{j}$ are the $j^{t h}$ bus voltage magnitude and angle, $X_{i j}$ is the line reactance, and $\delta_{i j}$ is the phase angle between sending end and receiving end voltages. Thus, from the equation (1), it is clear that the power flow is a function of transmission line impedance, the magnitude of the sending end and receiving end voltages and the phase angle between the voltages. By controlling one or a combination of the power flow arrangements, it is possible to control the active as well as the reactive power flows on the transmission line. With FACTS devices, such as Static Var Compensator (SVC), Static Synchronous Compensator (STATCOM), Static Synchronous Series Compensator (SSSC) and Unified Power Flow Controller (UPFC) etc., it is possible to regulate rapidly and flexibly the bus voltages, line impedances and phase angles in the power system. These FACTS controllers, which are based on voltage source converters, can facilitate the power flow control, enhance the power transfer capability, decrease the generation cost, and improve the security and stability of the power system [1]-[2].

A Static Synchronous Series Compensator (SSSC) is a power electronic-based synchronous voltage source which is connected in series with a power system. It consists of a solid state voltage source converter which generates a controllable ac voltage at fundamental frequency. When the series injected voltage leads the line current, it can emulate as inductive or capacitive reactance so as to influence the power flow through the transmission line [3]-[6]. While the primary purpose of a SSSC is to control power flow in steady state, it can also improve transient stability of a power system [7].

The UPFC is also a member of the FACTS family with very attractive features [8]. The UPFC is able to control, simultaneously or selectively, all the parameters affecting power flow in the transmission line (voltage, impedance, and phase angle) [9]. It is recognized as the most sophisticated power flow controller currently, and probably the most expensive one. The UPFC, which consists of a series and a shunt converter connected by a common dc link capacitor, can simultaneously perform the 
function of transmission line real/reactive power flow control in addition to UPFC bus voltage/shunt reactive power control [10][11]. The shunt converter of the UPFC controls the UPFC bus voltage/shunt reactive power and the dc link capacitor voltage. The series converter of the UPFC controls the transmission line real/active power flows by injecting a series voltage of adjustable magnitude and phase angle [12]-[14], on the other hand, the series part known as SSSC can be controlled without restrictions. The phase angle of series voltage can be chosen independently from line current between 0 and $2 \pi$, and its magnitude is variable between zero and a defined maximum value. The parallel part known as STATCOM injects an almost sinusoidal current of variable magnitude at the point of connection. In this paper, $d-q$ control scheme is used for UPFC. This control scheme involves the transformation of a three-phase system (time-varying equations) to d-q two axis system (time-invariant set) through which the real and reactive power can be controlled individually. The performance of the $\mathrm{d}-\mathrm{q}$ control scheme based UPFC is compared with that of a SSSC in the presence of a single line-toground fault. The simulation results demonstrate that the $d-q$ control scheme based UPFC shows better power flow control performance as compared to SSSC.

\section{FACTS CONTROLLERS}

The basic principles of the following FACTS controllers, which are used in the power system under study, are discussed briefly.

\subsection{Static Synchronous Series Compensator (SSSC)}

The SSSC is a member of FACTS family used for power transmission series compensation. The basic configuration of a SSSC is shown in Fig. 1. It can be considered as a synchronous voltage source as it can inject an almost sinusoidal voltage of variable and controllable amplitude and phase angle, in series with a transmission line. The injected voltage is almost in quadrature with the line current. A small part of the injected voltage that is in phase with the line current provides the losses in

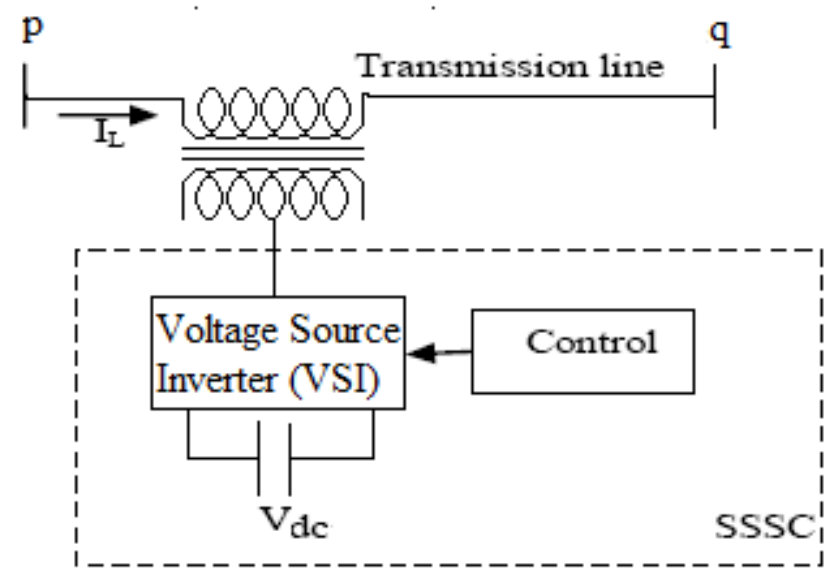

Fig. 1 Simplified diagram of a SSSC

the inverter. Most of the injected voltage, which is in quadrature with the line current, provides the effect of inserting an inductive or capacitive reactance in series with the transmission line. When the emulated reactance is inductive, the active and reactive power flow decrease and the effective reactance increases as the reactive compensation increases in the negative direction. When the emulated reactance is capacitive, the active and reactive power flow increase and the effective reactance decreases as the reactive compensation increases in the positive direction. Thus, the variable reactance influences the electric power flow on the transmission line.

\subsection{Unified Power Flow Controller (UPFC) and its d-q Control Scheme}

The UPFC is made out of two voltage-source converters (VSCs) with semiconductor devices having turn-off capability, sharing a common dc capacitor and connected to a power system through coupling transformers. The basic structure of a UPFC is shown in Fig. 2. The shunt converter is primarily used to provide the real power demand of the series converter at the common dc link terminal from the ac power system. It can also generate or absorb reactive power at its ac terminal, which is independent of the active power transfer to (or from) the de terminal. Therefore, with proper control, it can also fulfill the function of an independent advanced static VAR compensator providing reactive power compensation for the transmission line and thus executing indirect voltage regulation at the input terminal of the UPFC.

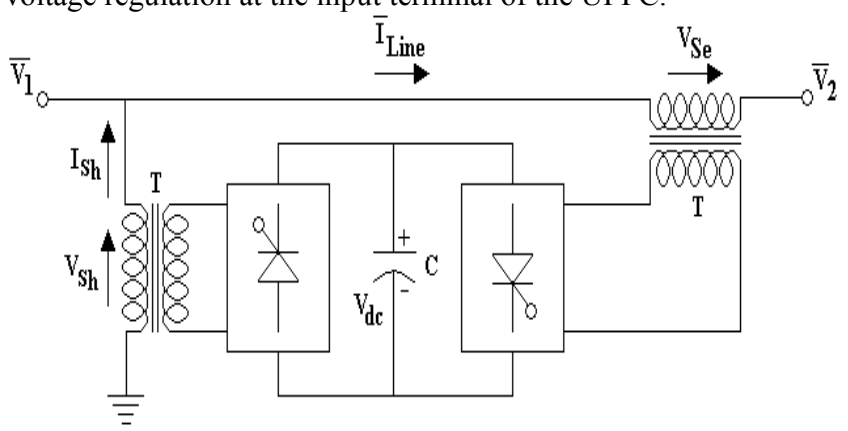

Fig. 2 Configuration of UPFC

The series converter is used to generate a voltage at the fundamental frequency with variable amplitude and phase angle, which is added to the ac transmission line by the series connected boosting transformer. The inverter output voltage injected in series with the line can be used for direct voltage control, series compensation, phase shifting, and their combinations. This voltage source can internally generate or absorb all the reactive power required by the different type of controls applied and transfers active power at its dc terminal. The reactive power is generated/absorbed independently by each converter and does not flow through the dc link [15]-[16]. The dc link provides a path to exchange active power between the converters. The series converter injects a voltage in series with the system voltage through a series transformer.

The power flow through the line can be regulated by controlling the magnitude and angle of the series-injected voltage. Therefore, the real power controller can significantly affect the level of reactive power flow. To produce relatively a fast response and hence to reduce the interaction between real and reactive power flow, a control scheme for a UPFC based on d-q axis theory was developed where the cross-coupling controller using d-q axis theory was applied to both the series converter [17] and the shunt converter [18] of the UPFC. The principle of cross-coupling controller is such that the q-axis voltage $V_{q}$ controls the d-axis 
current $I_{d}$ and the d-axis voltage $V_{d}$ controls the q-axis current $I_{q}$, thereby controlling both real and reactive powers independently. In this paper, the performance of $\mathrm{d}-\mathrm{q}$ control scheme applied to the shunt converter of UPFC has been compared with that of a SSSC.

\section{POWER SYSTEM UNDER STUDY}

Consider the single line diagram representation of a 3-phase power system with series FACTS devices as shown in Fig. 3. Here, the series FACTS devices such as UPFC (combination of STATCOM and SSSC) and SSSC are equipped between bus-2 and bus-3. The d-q control scheme based UPFC installed between bus- 2 and bus- 3 effectively controls the power flow from sending end to receiving end. A resistive load of suitable rating is connected at bus 1 . Here, $V_{S}$ and $V_{R}$ are assumed to be sending and receiving end voltages. This model assumes that sending end corresponds to a power plant while the receiving end to an electric power network. The system parameters are shown in Table 1 .

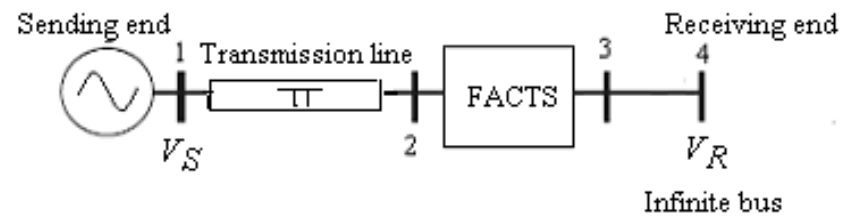

Fig. 3 Single line diagram of a 3-phase power system with FACTS device

Table 1: System Parameters

\begin{tabular}{|c|c|}
\hline Line to Line voltage & $230 \mathrm{kV}$ \\
\hline Frequency & $60 \mathrm{~Hz}$ \\
\hline Transmission line rating & $150 \mathrm{MVA}$ \\
\hline Capacitance of DC link capacitor & $3000 \mu \mathrm{F}$ \\
\hline DC link voltage & $38 \mathrm{kV}$ \\
\hline Length of transmission line & $600 \mathrm{~km}$ \\
\hline Resistance of transmission line & $0.01273 \Omega / \mathrm{km}$ \\
\hline Inductance of transmission line & $0.9337 \mathrm{mH} / \mathrm{km}$ \\
\hline Capacitance of transmission line & $12.74 \mathrm{nF} / \mathrm{km}$ \\
\hline
\end{tabular}

\section{SIMULATION \\ DISCUSSION}

RESULTS

AND

The power system model shown in Fig. 3 is simulated in Matlab/Simulink environment. Initially, a SSSC is placed in series with the transmission line. A single line-to-ground (L-G) fault, on phase-a, of three-cycles duration is made to occur near bus 1 . The variations in sending end and receiving end real and reactive powers, and the 3-phase currents $I_{a}, I_{b}$ and $I_{c}$ are shown in Figs. 4-6.

Next, the SSSC is replaced by a d-q control scheme based UPFC in the power system model. A single line-to-ground (L-G) fault, on phase-a, of three-cycles duration is made to occur near bus 1 .
The variations in sending end and receiving end real and reactive powers, and the 3-phase currents $I_{a}, I_{b}$ and $I_{c}$ are shown in Figs. 7-9.

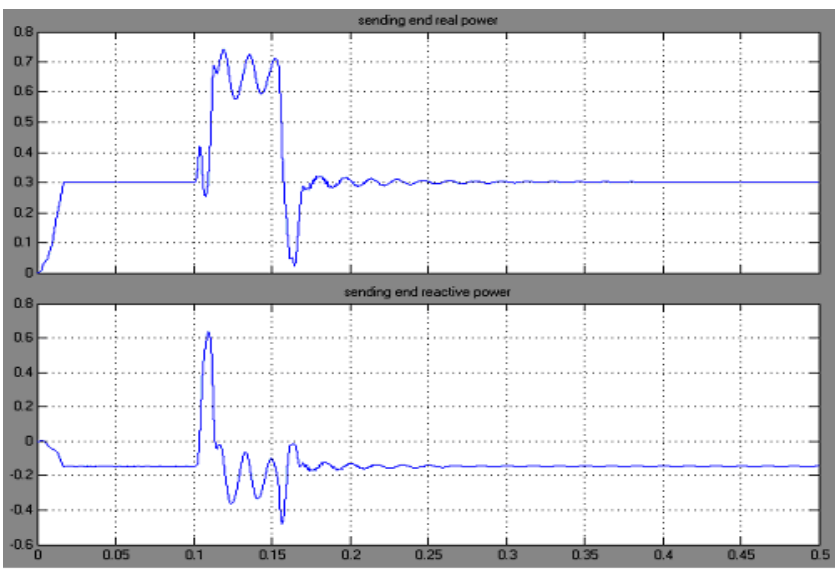

Fig. 4 Variation of sending end real and reactive powers (pu) wrt time (s) with SSSC

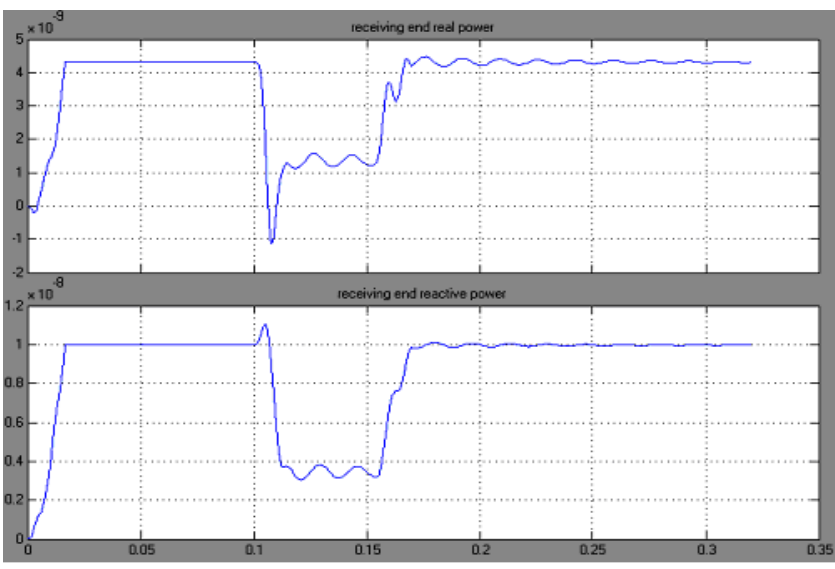

Fig. 5 Variation of receiving end real and reactive powers (pu) wrt time (s) with SSSC

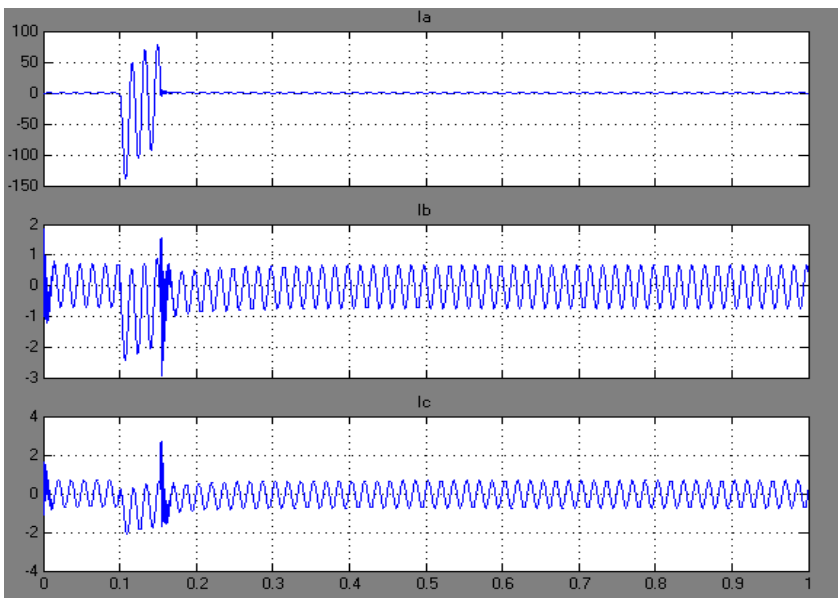

Fig. 6 Variation of 3-phase currents $I_{a}, I_{b}$ and $I_{c}$ (amperes) wrt time (s) with SSSC 


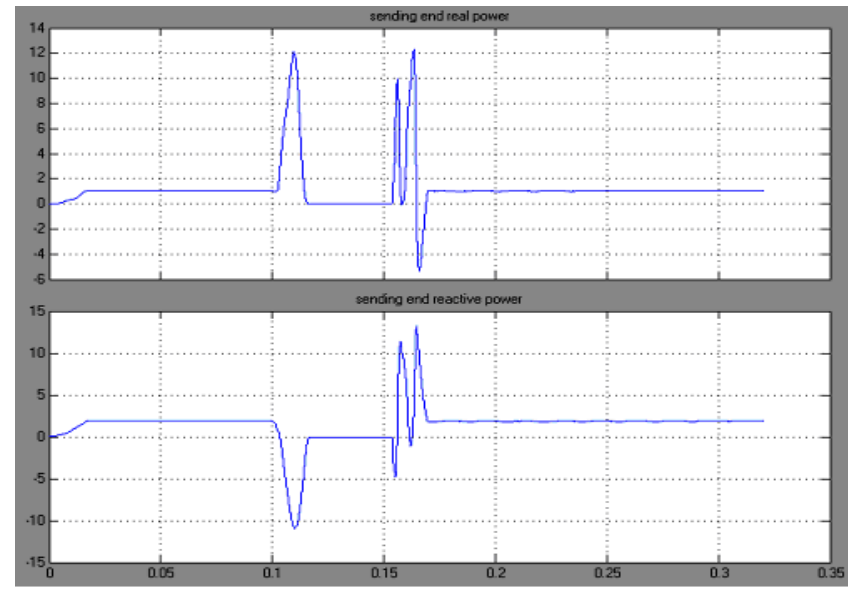

Fig. 7 Variation of sending end real and reactive powers (pu) wrt time (s) with UPFC

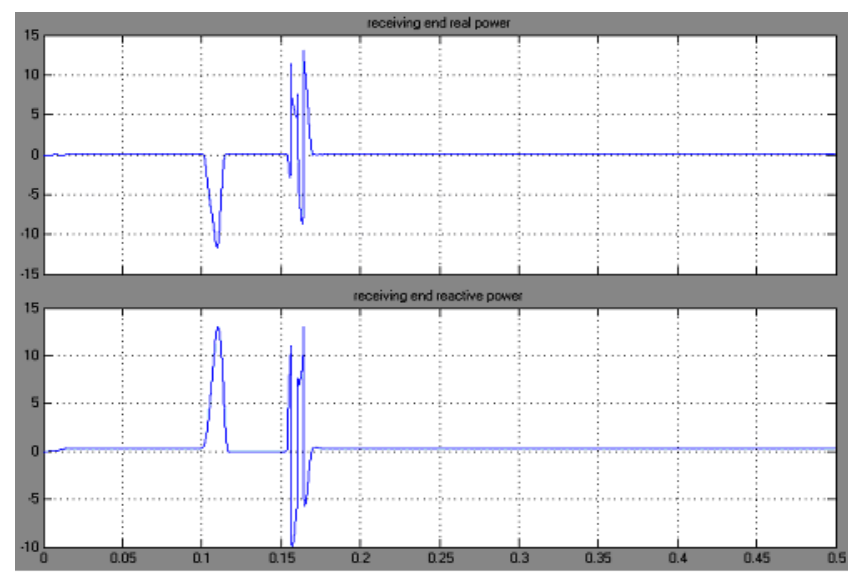

Fig. 8 Variation of receiving end real and reactive powers wrt time (s) with UPFC

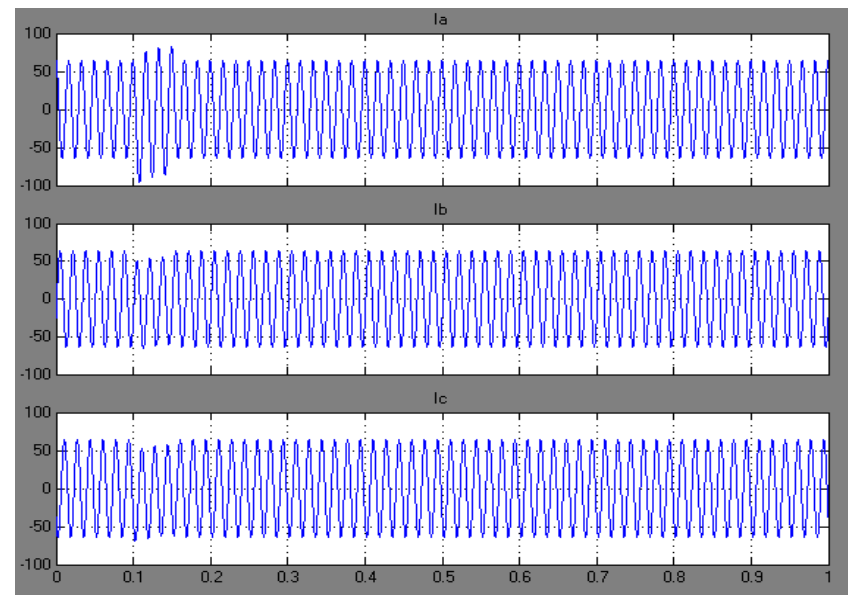

Fig. 9 Variation of 3-phase currents $I_{a}, I_{b}$ and $I_{c}$ (amperes) wrt time (s) with UPFC
From the simulation results, it is inferred that the transmission capability of the existing transmission line is highly improved with the presence of $\mathrm{d}-\mathrm{q}$ control scheme based UPFC than with the presence of SSSC. But the difference between the sending end and receiving end real power is somewhat high in the transmission line with UPFC or SSSC. This is due to the increase in the transmission line losses, which include losses in the converters and coupling transformers. The power transfer capability of long transmission lines is usually limited by their thermal capability. Utilizing the existing transmission line at its maximum thermal capability is possible with UPFC.

The series inverter injects voltage of variable magnitude and phase into the transmission line at the point of its connection, thereby controlling real and reactive power flow through the line. The active power flow through the line is supplied by SSSC. This real power is obtained from the DC source connected to its DC terminals. The shunt inverter provides the required power to the series inverter through the DC link.

\section{CONCLUSION}

In this study, the Matlab/Simulink environment is used to simulate a simple 3-phase power system with UPFC connected to a three-phase three-wire transmission system. The d-q axis control performance of UPFC intended for installation on a transmission line is presented. From the simulation results, it is inferred that by implementing d-q control scheme to the shunt converter of UPFC, it is possible to achieve fast power flow control and to reduce the interaction between real and reactive power flow. There is an improvement in the real and reactive power flow through the transmission line with UPFC when compared to the system with SSSC.

\section{REFERENCES}

[1] N.G. Hingorani, 1988, "High Power Electronics and Flexible AC Transmission System,” IEEE Power Eng. REV.

[2] B.M. Zhang and Q.F. Ding, 1997, "The Development of FACTS and its Control," Proc. APSCOM-97, Hong Kong.

[3] R.M. Mathur, R.K. Varma, 2002, "Thyristor-based FACTS Controllers for Electrical Transmission Systems," IEEE Press, Piscataway.

[4] K.K. Sen, 1998, "SSSC - Static Synchronous Series Compensator: Theory, Modeling and Application," IEEE Transactions on Power Delivery, 13(1), pp. 241-246.

[5] L. Gyugyi, 1994, "Dynamic Compensation of AC Transmission Line by Solid State Synchronous Voltage Sources," IEEE Transactions on Power Delivery, 9(22), pp. 904-911.

[6] Prechanon Kumkratug, Panthep Laohachai, 2007, "Direct Method of Transient Stability Assessment of a Power System with a SSSC," Journal of Computers, 2(8), pp. 77-82.

[7] Akhilesh A. Nimje, Chinmoy Kumar Panigrahi, Ajaya Kumar Mohanty, 2011, "Enhanced Power Transfer Capability by using SSSC," Journal of Mechanical Engineering Research, 3(2), pp. 48-56.

[8] I. Musirin, N. Diamah, M. Radzi, M. Murtadha Othman, M. Khayat Idris, and T. Khawa Abdul Rahman, 2008, "Voltage 
Profile Improvement using Unified Power Flow Controller via Artificial Immune System," WSEAS Transactions on Power Systems, 3(4), pp. 194-204.

[9] L. Gyugyi, C.D. Schauder, S.I. Williams, T.R. Reitman, D.R. Torgerson, and A. Edris, 1995, "The Unified Power Flow Controller: A new approach to power transmission control," IEEE Transactions on Power Delivery, 10(2), pp. 10851097.

[10] M. Noroozian, L. Angquist, M. Ghandhari, G. Andersson, 1997, "Use of UPFC for Optimal Power Flow Control," IEEE Transactions on Power Delivery, 12(4), pp. 16291634.

[11] B.A. Renz, A. Keri, A.S. Mehraben, C. Schauder, E. Stacey, I. Kovalsky, L. Gyugyi, and A. Edris, 1999, "AEP Unified Power Flow Controller Performance," IEEE Transactions on Power Delivery, 14(4), pp. 1374-1381.

[12] I. Papic, P. Zunko, and D. Povh, 1997, "Basic Control of Unified Power Flow Controller," IEEE Transactions on Power Systems, 12(4), pp. 1734-1739.
[13] P. Kumkratug, M.H. Haque, 2003, "Versatile Model of a Unified Power Flow Controller in Simple System," IEE Proc. Gener. Transm. \& Distrib., 150(2), pp. 155-161.

[14] L. Gyugui, 1992, “A Unified Power Flow Control Concept of Flexible AC Transmission Systems," IEE Proceedings-C, 139(4), pp. 323-331.

[15] Prechanon Kumkratug, 2009, "Application of UPFC to Increase Transient Stability of Inter-Area Power System," Journal of Computers, 4(4), pp. 283-287.

[16] J. Bian, D.G. Ramey, R.J. Nelson, and A. Edris, 1997, “A Study of Equipment Sizes and Constraints for a Unified Power Flow Controller," IEEE Transactions on Power Delivery, 12(3), pp. 1385-1391.

[17] Q. Yu, S.D. Round, L.E. Norum, and T.M. Undeland, 1996, "Dynamic Control of a Unified Power Flow Controller," IEEE Transactions on Power Delivery, 9(2), pp. 508-514.

[18] S. Tara Kalyani and G. Tulsiram Das, 2007, "Simulation of D-Q Control System for a Unified Power Flow Controller," ARPN Journal of Engineering and Applied Sciences, 2(6), pp. 10-19. 